\title{
Erratum
}

https://doi.org/10.1631/jzus.A20e0314

Check for updates

\section{Erratum to: Effects of the geometrical parameters of the injection nozzle on ethylene-air continuous rotating detonation}

Wei-jie FAN, Jin ZHOU ${ }^{\bowtie}$, Shi-jie LIU, Hao-yang PENG

Science and Technology on Scramjet Laboratory, College of Aerospace Science and Technology, National University of Defense Technology, Changsha 410073, China

Erratum to: J Zhejiang Univ-Sci A (Appl Phys \& Eng) 2021 22(7):547-563 https://doi.org/10.1631/jzus.A2000314

The original version of this article unfortunately contained a mistake.

In line 22, p. 550, “ $A T^{b}\left(\frac{-E_{\mathrm{a}}}{R T}\right)$ " should be “ $A T^{b} \exp \left(\frac{-E_{\mathrm{a}}}{R T}\right)$ " in Eq. (1), i.e. "The chemical reaction is treated by a laminar finite rate reaction model and the reaction rate constants are determined by the Arrhenius formulation, i.e. $k_{\mathrm{f}}=A T^{b} \exp \left(\frac{-E_{\mathrm{a}}}{R T}\right)$." 